\title{
Association between rotating night shift work and metabolic syndrome in Korean workers: differences between 8-hour and 12-hour rotating shift work
}

\author{
Jae-Il OH ${ }^{1}$ and Hyeon Woo YIM ${ }^{2 *}$ \\ ${ }^{1}$ Department of Public Health, The Catholic University of Korea, Republic of Korea \\ ${ }^{2}$ Department of Preventive Medicine, College of Medicine, The Catholic University of Korea, Republic of Korea \\ Received May 14, 2017 and accepted October 7, 2017 \\ Published online in J-STAGE October 19, 2017
}

\begin{abstract}
This study aimed to analyze the association between the shift work schedule and metabolic syndrome (MetS). This is a retrospective longitudinal study based on the 2015 health checkup data of 2,090 workers evaluated for MetS in 2010 at a general hospital in Korea. The participants were divided according to their shift work schedule into daytime, three-shift (8-h rotation), and twoshift (12-h rotation) workers. The index that indicates the association between the shift work schedule and MetS is the odds ratio (OR) calculated using multivariate logistic regression. The analysis for the entire group of workers indicated that there was positive association between two-shift rotation and MetS $(\mathrm{OR}=1.58,95 \%$ confidence interval $[\mathrm{CI}]: 1.09,2.29)$. In the analysis of rotating nightshift workers, the years of rotating night shifts, frequency of night-shift work, and sleep disturbance were added to the confounding variables, and two-shift work remained positively associated with MetS $(\mathrm{OR}=1.72,95 \%$ CI: 1.10, 2.70). The risk of MetS differs based on the shift work schedules they engage in. Hence, structural changes to the shift work schedules are required to prevent MetS in night-shift workers.
\end{abstract}

Key words: Metabolic syndrome, Rotating night shift work, Retrospective longitudinal study, Three-shift rotation, Two-shift rotation

\section{Introduction}

The 24-hour-a-day production schedule of the manufacturing industry and changes to the human use of services have made night-shift work mandatory. In Europe, $19 \%$ of the entire workforce engages in night-shift work ${ }^{1)}$. In Korea, according to the Ministry of Employment and Labor's 2011 research that sampled 3,413 firms, 15.2\% of the entire workforce was engaged in night-shift work ${ }^{2)}$. Rotation shifts that include night shifts are known to predispose to obesity ${ }^{3,4)}$, high blood pressure ${ }^{5,6)}$, dyslipid-

*To whom correspondence should be addressed.

E-mail: y1693@catholic.ac.kr

C2018 National Institute of Occupational Safety and Health emia $^{7)}$, and diabetes ${ }^{8,9)}$. From 2014, the Korean government made monitoring of night-shift work exposure and the health of night-shift workers mandatory.

Metabolic syndrome (MetS) is defined as a cluster of risk factors for diabetes and cardiovascular diseases (CVDs). The prevention of MetS is believed to decrease the prevalence of diabetes and CVDs, and as such, MetS prevention is an important health focus worldwide ${ }^{10)}$. While many studies report that rotating night-shift work is a risk factor for MetS, this finding is not consistent ${ }^{11-16)}$. Since the scheduling of night-shift work determines the frequency and extent to which the worker is exposed to night-shift work, it is an important workplace factor for evaluating the risk of MetS. However, very few studies have classified night-shift work by rotation in order to examine the 


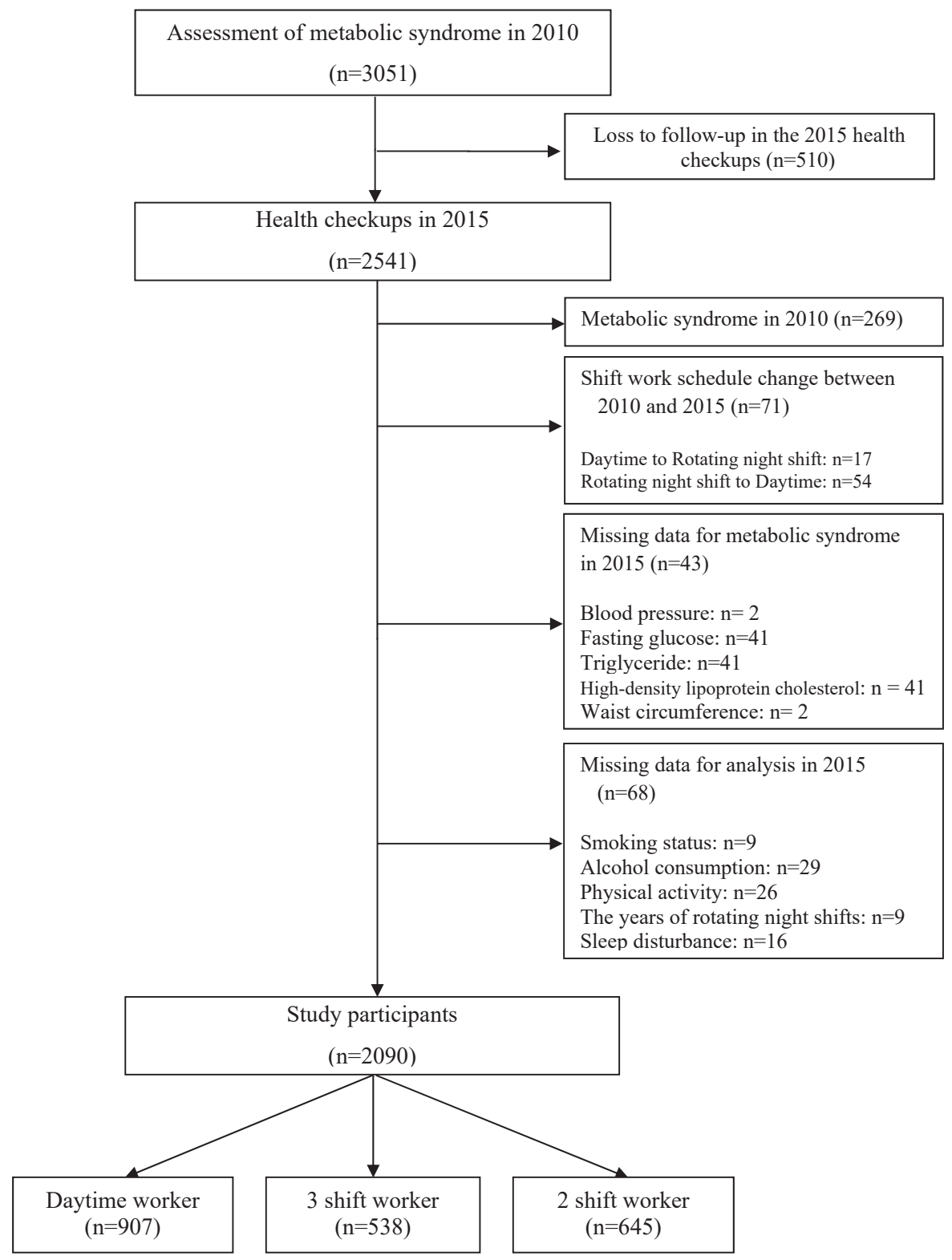

Fig. 1. Selection of study participants.

association between rotating night-shift work and MetS. Thus, the aim of this study was to evaluate the association between rotating shift schedule and MetS.

\section{Methods}

\section{Study design and population}

This retrospective longitudinal study utilized worker health checkup data obtained on a per-workplace basis from a tertiary hospital located in Ansan City, Korea. Thirty-one workplaces had their workers evaluated for MetS at the hospital in 2010. They were all manufacturing companies located in the Ansan-Siheung industrial complex and with rotating shift schedule. These workplaces also conducted health checkups for their workers at the same hospital in 2015. A total of 3,051 workers aged between 20 and $59 \mathrm{yr}$ who were assessed for MetS in 2010 were selected. Of these, 2,090 were included in this study after excluding workers with the following conditions: employees who did not undergo health checkups in 2015 at this hospital $(n=510)$; those who were diagnosed with MetS in 2010 ( $n=269)$; those who had a change of the shift work schedule between 2010 and $2015(n=71)$; those who had some missing test items necessary for diagnosis of MetS in 2015 ( $n=43)$; or those who lacked data on confounding variables for analysis $(\mathrm{n}=68)$ (Fig. 1). 
The 2010 and 2015 data of occupational factors such as engagement in night-shift work, shift work schedule, and years of rotating night shifts were provided by the managers of the employee health affairs of each company. The workers who engaged in night-shift work are required to fill in the questionnaire for night-shift work during their health checkups. This questionnaire contained questions such as shift work schedule, years of rotating night shifts, and frequency of night-shift work. The 2015 data of this questionnaire were used as supplemental data in this study. The physician rechecked all examinees regarding their engagement in night-shift work, shift work schedule, type of job, years of rotating night shifts, frequency of nightshift work, and change of shift work schedule between 2010 and 2015 during the medical examination. Health checkups were carried out in the morning at the respective workplaces. The medical staff instructed the workers to fast for at least $8 \mathrm{~h}$ prior to the health checkup. This study was approved by the Institutional Review Board of the Catholic University of Korea, and the requirement for informed consent was waived since data were collected retrospectively without any participant-identifying information.

\section{Assessment of rotating night-shift work}

This study defined night-shift work and night-shift workers as per the regulations of the Ministry of Employment and Labor of Korea ${ }^{17)}$.

- Night-shift work: Work performed between 10 p.m. and 6 a.m.

- Night-shift worker: A worker that satisfies either of the following two criteria:

1. Engaged in night-shift work for over $60 \mathrm{~h}$ per month over 6 months.

2. Carried out an average of four or more shifts of work between 10 p.m. and 6 a.m. continuously, over the period of 6 months.

Night-shift work was comprised of either three 8-h rotating shifts or two 12-h rotating shifts. The 8 -h rotating shift was made up of a morning, an evening, and a night shift. The 12-h rotating shift consisted of a day shift and a night shift. Of the 31 workplaces, 8 operated an 8 -h rotating shift pattern; 21, a 12-h pattern; 2, both shift patterns.

\section{Assessment of MetS}

The diagnosis of MetS in this study was based on the modified NCEP ATP III criteria $^{18)}$. A worker was diagnosed with MetS if they satisfied three or more out of the five following criteria: 1) elevated blood pressure $\geq 130 / 85$
$\mathrm{mmHg}$ or receiving treatment for hypertension; 2) elevated fasting plasma glucose level $\geq 100 \mathrm{mg} / \mathrm{dl}$ or receiving treatment for elevated blood glucose; 3 ) high serum level of triglyceride $\geq 150 \mathrm{mg} / \mathrm{dl}$ or receiving treatment for dyslipidemia; 4) low serum level of high-density lipoproteins (HDL) cholesterol: men $<40 \mathrm{mg} / \mathrm{dl}$, women $<50 \mathrm{mg} / \mathrm{dl}$ or receiving treatment for dyslipidemia; 5) waist circumference: men $\geq 90 \mathrm{~cm}$, women $\geq 80 \mathrm{~cm}$. The same equipment and methods were used for measuring MetS components in 2010 and in 2015. Waist circumference and blood pressure were measured by nurses, and fasting glucose, triglyceride, and HDL cholesterol were measured using Modular P800 (Roche, Swiss).

\section{Assessment of confounding variables}

Smoking status, alcohol consumption, and the physical activity of workers were evaluated using medical history taking and self-administrated questionnaires in 2015. Smoking status was classified into current smokers and non-smokers. Current smoker is defined as a person who has smoked 100 cigarettes in his or her lifetime and who currently smokes cigarettes. Using the criteria of the National Institute on Alcohol Abuse and Alcoholism, alcohol consumption was divided into three groups: none, lowrisk drinking, and high-risk drinking. We defined highrisk drinking as $\geq 5$ glasses/d or $\geq 15$ glasses/wk for men and $\geq 4$ glasses/d or $\geq 8$ glasses/wk of alcohol for women. We defined one glass as $50 \mathrm{ml}$ of soju (distilled liquor in Korea). Physical activity levels were measured using the Korean version of the International Physical Activity Questionnaire (IPAQ), short form ${ }^{19}$. According to IPAQ, physical activity can be categorized into three levels: high, moderate, and $l o w^{20)}$. In this study, if the physical activity of workers were moderate or above $(\geq 600$ MET-min/ wk), this was classified as sufficient physical activity. The size of the workplace was classified into large $(\geq 300$ workers) and medium (50-299 workers). There were no small workplaces with $<50$ workers among the workplaces selected for the study. The type of job performed by the workers in this study was either white or blue collar. White-collar work included office, research, and management roles; blue-collar work included manufacturing, operation and maintenance, and transportation and logistics roles. The data of years of rotating night shifts and frequency of night-shift work were collected in the form of continuous variables. The frequency of night-shift work is evaluated as the average number of night-shift per month over a period of 6 months. Evaluation of sleep disturbance was carried out in night-shift workers using the Insomnia 
Severity Index (ISI) ${ }^{21)}$. The Korean version of the ISI is reported to be a reliable and valid instrument for assessing insomnia severity in Koreans ${ }^{22}$. The total score is interpreted as follows: $0-7$, no clinically significant insomnia; $8-14$, subthreshold insomnia; $15-28$, clinical insomnia.

\section{Statistical analysis}

For the statistical analysis, the study participants were divided into daytime, three-shift (8-h rotation), and twoshift (12-h rotation) workers. We evaluated the differences among the groups using chi-square tests for categorical variables, and we also conducted post hoc tests after chisquare tests using Dunnett's test. The $t$-test was used for continuous variables between two- and three-shift rotations. Confounding variables were adjusted using multivariate logistic regression. Variables shown to have a statistically significant relationship with MetS in the univariate logistic regression $(p \leq 0.2)$ were included in the multivariate logistic regression model as confounding variables. The results after adjusting for confounding variables are shown as odds ratio (OR) for three- and two-shift rotation, with the daytime as the reference group. First, variables were added in phases for different models for all the workers: model 1 , adjusted for age and sex; model 2, additionally adjusted for smoking status (current smoker/non-smoker), alcohol consumption (no/social/heavy), and physical activity (sufficient/insufficient); model 3 , additionally adjusted for workplace size ( $\geq 300$ workers/50-299 workers) and type of job (white-collar/blue-collar). Additional analysis using multivariate logistic regression was performed for the rotating night-shift workers alone. For rotating night-shift workers, the three-shift rotation was used as the reference group, and the OR for the two-shift rotation was calculated. Moreover, additional variables of years of night-shift rotating, frequency of night-shift work, and sleep disturbance were added, which were not relevant to daytime workers: model 1, adjusted for age and sex; model 2, additionally adjusted for smoking status, alcohol consumption, and physical activity; model 3 , additionally adjusted for workplace size and type of job, years of rotating night shifts (continuous), frequency of night-shift work (continuous), and sleep disturbance (no/subclinical/ clinical). Of 3,051 workers, 510 who were evaluated for MetS in 2010 were lost to follow-up in the 2015 health checkup. For these 510 workers, only sex, age, and MetS prevalence rate of 2010 were confirmed. With regard to the MetS prevalence rate in 2010, sex, and age distribution, 510 workers lost to follow-up were compared with the 2,541 workers who received health checkups at the hospi- tal in 2015 using chi-square test. SPSS 18 (IBM SPSS Inc., Chicago, IL, USA) was utilized for the statistical analyses.

\section{Results}

The study participants $(n=2,090)$ were divided into three groups depending on their shift work schedule: daytime, three-shift rotation, and two-shift rotation. Among the participants, 907 worked daytimes, 538 worked threeshift rotation, and 645 worked two-shift rotation. The proportion of female and white-collar workers was higher in the daytime group than in the other two groups. The twoshift rotation group had the lowest proportion of workers who work at large-size workplaces among the three groups. Otherwise, the smoking and drinking rates of the two-shift rotation group were higher than the other two groups. The three-shift rotation group was older than the other two groups and had the highest percentage of workers in large-size workplaces. The years of rotating night shifts and the frequency of night-shift work were longer and higher, respectively, in the three-shift rotation group than in the two-shift rotation group (Table 1).

In multivariate logistic regression analysis conducted with the three groups, two-shift rotation was positively associated with MetS in all models: model $1, \mathrm{OR}=1.53$, 95\% confidence interval [CI]: 1.13, 2.09; model 2, $\mathrm{OR}=1.51,95 \%$ CI: $1.11,2.06$; model $3, \mathrm{OR}=1.58,95 \%$ CI: 1.09, 2.29. However, there was no association between three-shift rotation and MetS in any of the models (Table 2).

The multivariate logistic regression analysis including the rotating night-shift workers alone, where the years of rotating night shifts, the frequency of the night-shift work, and sleep disturbance were added as confounding variables, continued to indicate that two-shift rotation was associated with MetS $(\mathrm{OR}=1.72,95 \%$ CI: $1.10,2.70)$ (Table 3).

The results of the comparison between workers lost to follow-up and workers who received health check in 2015 showed a significant difference only in age distribution. Among the workers lost to follow-up, the percentage of workers in their $20 \mathrm{~s}$ was high (Table 4).

\section{Discussion}

A leading mechanism that explains the association between night-shift work and MetS is circadian misalignment. The suprachiasmatic nucleus of the anterior hypothalamus controls the endogenous circadian rhythm, which 
Table 1. Characteristics of the sample by shift work schedule

\begin{tabular}{|c|c|c|c|c|}
\hline Variables & Daytime $(\mathrm{n}=907)$ & Three-shift rotation $(\mathrm{n}=538)$ & Two-shift rotation $(\mathrm{n}=645)$ & $p$-value ${ }^{\mathrm{a}}$ \\
\hline Sex & & & & $<0.001^{* * *}$ \\
\hline Male & 775 (85.4) & $495(92.0)$ & $602(93.3)$ & \\
\hline Female & $132(14.6)$ & $43 \quad(8.0)$ & $43 \quad(6.7)$ & \\
\hline Age (years) & & & & $<0.001^{* * *}$ \\
\hline $25-34$ & 96 (10.6) & $28 \quad(5.2)$ & $38 \quad(5.9)$ & \\
\hline $35-44$ & $399(44.0)$ & $187(34.8)$ & $334(51.8)$ & \\
\hline $45-54$ & $292(32.2)$ & $257(47.8)$ & $212(32.9)$ & \\
\hline $55-64$ & $120(13.2)$ & $66(12.3)$ & $61 \quad(9.5)$ & \\
\hline Smoking status & & & & $<0.001^{* * *}$ \\
\hline Non-smoker & $605(66.7)$ & $334(62.1)$ & $352(54.6)$ & \\
\hline Current smoker & $302(33.3)$ & 204 (37.9) & $293(45.4)$ & \\
\hline Alcohol consumption & & & & $0.015^{*}$ \\
\hline None & $283(31.2)$ & $189(35.1)$ & $174(27.0)$ & \\
\hline Low-risk drinking & $207(22.8)$ & $98(18.2)$ & $139(21.6)$ & \\
\hline High-risk drinking & $417(46.0)$ & $251(46.7)$ & $332(51.5)$ & \\
\hline Physical activity & & & & 0.360 \\
\hline Sufficient & $427(47.1)$ & $271(50.4)$ & $300(46.5)$ & \\
\hline Insufficient & $480(52.9)$ & $267(49.6)$ & $345(53.5)$ & \\
\hline Workplace size & & & & $<0.001^{* * *}$ \\
\hline Medium(50-299 workers) & $321(35.4)$ & $141(26.2)$ & $278(43.1)$ & \\
\hline Large ( $\geq 300$ workers) & $586(64.6)$ & $397(73.8)$ & $367(56.9)$ & \\
\hline Type of job & & & & $<0.001^{* * *}$ \\
\hline White-collar & $539(59.4)$ & $50 \quad(9.3)$ & $30 \quad(4.7)$ & \\
\hline Blue-collar & $368(40.6)$ & $488(90.7)$ & $615(95.3)$ & \\
\hline Metabolic syndrome & & & & $0.009^{* *}$ \\
\hline Yes & $93(10.3)$ & $59(11.0)$ & $98(15.2)$ & \\
\hline No & $814(89.7)$ & $479(89.0)$ & $547(84.8)$ & \\
\hline Sleep disturbance ${ }^{\mathrm{c}}$ & & & & 0.170 \\
\hline No & & $317(58.9)$ & $355(55.0)$ & \\
\hline Subthreshold insomnia & & $170(31.7)$ & $208(32.2)$ & \\
\hline Clinical insomnia & & $51 \quad(9.5)$ & $82(12.7)$ & \\
\hline Years of rotating night shifts (year) ${ }^{\mathrm{bc}}$ & & $15.8 \pm 6.3$ & $13.5 \pm 5.9$ & $0.02 *$ \\
\hline Frequency of night shift work ${ }^{\mathrm{bc}}$ & & $8.3 \pm 0.7$ & $10.3 \pm 1.7$ & $<0.001^{* * *}$ \\
\hline
\end{tabular}

Values for categorical variables given as number (percentage); Values for continuous variables given as mean $\pm \mathrm{SD}$.

${ }^{*} p<0.05,{ }^{* *} p<0.01,{ }^{* * *} p<0.001$.

${ }^{a} \chi^{2}$ test, categorical variables; $t$-test, continuous variables.

${ }^{\mathrm{b}}$ Continuous variables.

${ }^{\mathrm{c}}$ Variables for rotating night shift workers.

Table 2. Odds ratios of metabolic syndrome by the shift work schedule ${ }^{a}$

\begin{tabular}{|c|c|c|c|c|c|c|}
\hline & \multicolumn{2}{|r|}{ Model $1^{\text {b }}$} & \multicolumn{2}{|r|}{ Model $2^{\mathrm{c}}$} & \multicolumn{2}{|r|}{ Model $3^{\mathrm{d}}$} \\
\hline & OR & $95 \%$ CI & OR & $95 \% \mathrm{CI}$ & OR & $95 \% \mathrm{CI}$ \\
\hline Daytime & 1 & Reference & 1 & Reference & 1 & Reference \\
\hline Three-shift rotation & 0.96 & $(0.68-1.36)$ & 0.97 & $(0.68-1.38)$ & 0.98 & $(0.66-1.45)$ \\
\hline Two-shift rotation & 1.53 & $(1.13-2.09)^{*}$ & 1.51 & $(1.11-2.06)^{*}$ & 1.58 & $(1.09-2.29)^{*}$ \\
\hline
\end{tabular}

Abbrevations: OR, odds ratio; $\mathrm{CI}$, confidential interval.

${ }^{*} p<0.05,{ }^{* *} p<0.01,{ }^{* * *} p<0.001$.

${ }^{\mathrm{a}}$ ORs were calculated by multivariate logistic regression.

${ }^{\mathrm{b}}$ Model 1 was adjusted for age and sex.

${ }^{\mathrm{c}}$ Model 2 was additionally adjusted for smoking status (current smoker/non-smoker), alcohol consumption (no/social/heavy) and physical activity (sufficient/insufficient).

${ }^{\mathrm{d}}$ Model 3 was additionally adjusted for workplace size ( $\geq 300$ workers/50-299 workers) and type of job (white/blue-collar). 
Table 3. Odds ratios of metabolic syndrome by shift work schedule among night shift worker $^{\mathrm{a}}$

\begin{tabular}{|c|c|c|c|c|c|c|}
\hline & \multicolumn{2}{|r|}{ Model $1^{\mathrm{b}}$} & \multicolumn{2}{|r|}{ Model $2^{\mathrm{c}}$} & \multicolumn{2}{|r|}{ Model $3^{\mathrm{d}}$} \\
\hline & OR & $95 \% \mathrm{CI}$ & OR & $95 \% \mathrm{CI}$ & OR & $95 \% \mathrm{CI}$ \\
\hline Three-shift rotation & 1 & Reference & 1 & Reference & 1 & Reference \\
\hline Two-shift rotation & 1.63 & $(1.15-2.33)^{*}$ & 1.61 & $(1.13-2.29)^{*}$ & 1.72 & $(1.10-2.70)^{*}$ \\
\hline
\end{tabular}

Abbrevations: OR, odds ratio; $\mathrm{CI}$, confidential interval.

${ }^{*} p<0.05,{ }^{* *} p<0.01,{ }^{* * *} p<0.001$.

${ }^{a}$ ORs were calculated by multivariate logistic regression.

${ }^{\mathrm{b}}$ Model 1 was adjusted for age and sex.

${ }^{\mathrm{c}}$ Model 2 was additionally adjusted for smoking status (current smoker/non-smoker), alcohol consumption (no/social/heavy) and physical activity (sufficient/insufficient).

${ }^{d}$ Model 3 was additionally adjusted for workplace size ( $\geq 300$ workers/50-299 workers), type of job (white/blue-collar), the years of rotating night shifts (continuous), the frequency of night shift work (continuous), and sleep disturbance (no/subclinical/clinical).

Table 4. Characteristics of the population who participated in the 2010 health checkups

\begin{tabular}{|c|c|c|c|c|}
\hline \multirow[b]{2}{*}{ Variables } & \multirow{2}{*}{$\begin{array}{c}\text { Total } \\
(\mathrm{n}=3,051)\end{array}$} & \multicolumn{2}{|c|}{ Participated health checkups } & \multirow[b]{2}{*}{$p$-value } \\
\hline & & $\begin{array}{l}2010 \text { and } 2015 \\
\quad(\mathrm{n}=2,541)\end{array}$ & $\begin{array}{c}2010 \text { only } \\
(\mathrm{n}=510)\end{array}$ & \\
\hline Gender & & & & 0.557 \\
\hline Male & $2,770(90.8)$ & $2,303(90.6)$ & 467 (91.6) & \\
\hline Female & $281 \quad(9.2)$ & $238 \quad(9.4)$ & $43 \quad(8.4)$ & \\
\hline Age (years) & & & & $<0.001^{* * *}$ \\
\hline $20-29$ & $336(11.0)$ & $187(7.4)$ & $149(29.2)$ & \\
\hline $30-39$ & $1,286(42.2)$ & $1,097(43.2)$ & $189(37.1)$ & \\
\hline $40-49$ & $1,060(34.7)$ & $946(37.2)$ & $114(22.4)$ & \\
\hline $50-59$ & $369(12.1)$ & $311(12.2)$ & $58(11.4)$ & \\
\hline Metabolic Syndrome & & & & 0.209 \\
\hline Yes & $324(10.6)$ & $278(10.9)$ & $46 \quad(9.0)$ & \\
\hline No & $2,727(89.4)$ & $2,263(89.1)$ & $464(91.0)$ & \\
\hline
\end{tabular}

Values for categorical variables given as number (percentage). $p$-values calculated using $\chi^{2}$ test. ${ }^{*} p<0.05,{ }^{* *} p<0.01,{ }^{* * *} p<0.001$

affects the activity of a number of hormones such as the growth hormone, melatonin, cortisol, leptin, and ghre$\operatorname{lin}^{23,24)}$. As such, circadian misalignment between the endogenous circadian rhythm and the 24-h behavioral cycles caused by rotating night shifts disrupts the normal function of these hormones and negatively affects the maintenance of homeostasis of glucose and lipids ${ }^{24,25)}$. Several studies also report that circadian misalignment is common in shift workers, leading to increased blood glucose levels and blood pressure ${ }^{25,26)}$. Two-shift (12-h rotating shifts) workers have longer working hours in the night shift compared with three-shift (8-h rotating shift) workers. Moreover, two-shift work is composed of day and night shifts; thus, the frequency of night-shift work for workers are also greater compared to three-shift work, which includes morning, evening, and night shifts. Given such characteristics, it is possible that circadian misalignment occurs at a higher severity and proportion in two-shift workers compared with three-shift workers. This study also showed that the frequency of night-shift work for twoshift workers was higher than that for three-shift workers. We have included the frequency of night-shift work as a confounding variable in multivariate analysis. However, even after adjusting for the frequency of night-shift work, the risk of MetS was still increased in two-shift workers. Circadian misalignment is strongly associated with sleep deprivation on night-shift worker ${ }^{27)}$, and many studies suggest that sleep deprivation, comparatively more common for night-shift workers, is associated with $\mathrm{MetS}^{28-30}$. We used ISI in evaluating sleep disturbance, which has proven validity and reliability as an index for evaluating responses to insomnia treatment and as a screening instrument dur- 
ing primary care ${ }^{31)}$. However, in this study, the three- and two-shift workers had no meaningful differences in sleep disturbance.

The results of smoking habit, alcohol consumption, and physical activity in this study were similar to those of other studies. Previous studies have reported that night-shift workers are more likely to smoke and drink alcohol ${ }^{32-34)}$, and many studies have shown that physical activity does not differ between daytime and night-shift workers ${ }^{35-37)}$, similar to the results of this study. We could not obtain the data on the income levels of the workers in this study. In general, larger workplaces have higher income levels compared with smaller ones. The 2015 Labor Study on Employment Types also reported higher incomes for workplaces with $\geq 300$ workers compared with those workplaces with $<300$ workers $^{38)}$. As such, with the multivariate analysis adjusting the effects of workplace size, the influence of income levels is expected to adjust accordingly.

We have only confirmed one existing study conducted in Japan that evaluated the risk of MetS based on shift rotation type ${ }^{39)}$. However, contrary to this present study, the study in Japan reported that two-shift work was negatively associated with MetS (OR $=0.77,95 \% \mathrm{CI}$ : 0.61 , 0.98 ). We retrospectively used data from 2010 and could exclude workers who were diagnosed with MetS in 2010 in the analysis, but the Japanese study was cross-sectional. In addition, the present study followed the criteria of the modified NCEP ATP III for diagnosing MetS; however, the aforementioned study adhered to the standard Japanese criteria for diagnosing MetS. The standard Japanese criteria for the diagnosis of MetS, unlike the modified NCEP ATP III, have an essential component of waist circumference and have a higher fasting blood glucose standard ( $\geq 110$ $\mathrm{mg} / \mathrm{dl})$. Thus, it was difficult to compare the results of that study with those of the present study. The results of another study that examined daytime and two-shift workers were similar to the results of this study ${ }^{14,40}$. Studies that examined daytime and three-shift workers show different results between researchers. A study conducted in Finland found that the risk of MetS in three-shift workers did not increase compared to that of daytime workers, as observed in this current study ${ }^{41)}$; however, in a study conducted in France on 190 workers, three-shift work was positively associated with MetS ${ }^{13)}$. In this current study, $73.8 \%$ of the three-shift workers belonged to large workplaces ( $\geq 300$ workers). We believe that the difference of workplace size may have led to the differences in the results of the two studies.

The strength of this present study is that, unlike other studies on night-shift work and MetS, it further classified rotating night-shift workers into three- and two-shift workers to confirm their respective associations with MetS. Moreover, in this study, the classification of night-shift and daytime workers was carried out by the manager of employee health affairs of each company. Additionally, we rechecked their engagement in night-shift work and their working histories. As such, there was a lower possibility of misclassification for night-shift. Another strength of this study can be found in the participants, who worked with the same shift work schedule at the same workplace from 2010 to 2015. If retired workers and workers who were temporarily involved in rotating night-shift work are included in the study, the changes in shift work schedule may affect the outcome.

This study has several limitations. First, some of the confounding variables included in the analysis are crosssectional data. Second, we could not include the data of the workers' education level as a confounding variable. Lastly, there is no information on the workers' eating habits. However, the results of studies on the differences of the calorie intake between daytime and night-shift workers differ from each other ${ }^{13,42,43)}$. Results also differed in terms of meal frequency ${ }^{13,44)}$. This study was conducted with two- and three-shift workers as exposure groups who had rotating night-shift work for more than $5 \mathrm{yr}$, and two- and threeshift work are the most common types of rotating nightshift work. In addition, different types of manufacturing companies were included in this study. Therefore, it is possible to apply its results to rotating night-shift workers at manufacturing-related workplaces with $\geq 50$ workers. However, caution must be exercised in applying the results of this study to workers in other professions as well as to workers in workplaces with $<50$ workers.

In conclusion, the results of this study indicate that for night-shift workers, the risk of MetS would differ based on the shift work schedules they engage in. To prevent MetS in night-shift workers, structural changes to the shift work schedules are required, in addition to individual efforts on the part of workers such as lifestyle modifications.

\section{Acknowledgment}

We would like to thanks Editage (www.editage.com) for English language editing.

\section{Funding}

This research did not receive any specific grant from funding agencies in the public, commercial, or not-for- 
profit sectors.

\section{Conflict of Interest}

None declared.

\section{References}

1) Parent-Thirion A, Vermeylen G, van Houten G, et al. Fifth European Working conditions survey. Luxembourg: Publications Office of the European Union, 2012.

2) Park TJ, Paek DM, Park JS, et al (2012) The relationship between shift work and work-related injuries among Korean workers. Korean J Occup Environ Med 24, 52-60.

3) Kim MJ, Son KH, Park HY, Choi DJ, Yoon CH, Lee HY, Cho EY, Cho MC (2013) Association between shift work and obesity among female nurses: Korean Nurses' Survey. BMC Public Health 13, 1204. [Medline] [CrossRef]

4) Tada Y, Kawano Y, Maeda I, Yoshizaki T, Sunami A, Yokoyama Y, Matsumoto H, Hida A, Komatsu T, Togo F (2014) Association of body mass index with lifestyle and rotating shift work in Japanese female nurses. Obesity (Silver Spring) 22, 2489-93. [Medline]

5) Kubo T, Fujino Y, Nakamura T, Kunimoto M, Tabata H, Tsuchiya T, Kadowaki K, Odoi H, Oyama I, Matsuda S (2013) An industry-based cohort study of the association between weight gain and hypertension risk among rotating shift workers. J Occup Environ Med 55, 1041 - 5. [Medline] [CrossRef]

6) Guo Y, Liu Y, Huang X, Rong Y, He M, Wang Y, Yuan J, Wu T, Chen W (2013) The effects of shift work on sleeping quality, hypertension and diabetes in retired workers. PLoS One 8, e71107. [Medline] [CrossRef]

7) Dochi M, Suwazono Y, Sakata K, Okubo Y, Oishi M, Tanaka K, Kobayashi E, Nogawa K (2009) Shift work is a risk factor for increased total cholesterol level: a 14-year prospective cohort study in 6886 male workers. Occup Environ Med 66, 592-7. [Medline] [CrossRef]

8) Pan A, Schernhammer ES, Sun Q, Hu FB (2011) Rotating night shift work and risk of type 2 diabetes: two prospective cohort studies in women. PLoS Med 8, e1001141. [Medline] [CrossRef]

9) Vimalananda VG, Palmer JR, Gerlovin H, Wise LA, Rosenzweig JL, Rosenberg L, Ruiz Narváez EA (2015) Night-shift work and incident diabetes among AfricanAmerican women. Diabetologia 58, 699-706. [Medline] [CrossRef]

10) He D, Xi B, Xue J, Huai P, Zhang M, Li J (2014) Association between leisure time physical activity and metabolic syndrome: a meta-analysis of prospective cohort studies. Endocrine 46, 231-40. [Medline] [CrossRef]

11) Guo Y, Rong Y, Huang $X$, Lai H, Luo $X$, Zhang Z, Liu $Y$, He M, Wu T, Chen W (2015) Shift work and the relationship with metabolic syndrome in Chinese aged workers.
PLoS One 10, e0120632. [Medline] [CrossRef]

12) De Bacquer D, Van Risseghem M, Clays E, Kittel F, De Backer G, Braeckman L (2009) Rotating shift work and the metabolic syndrome: a prospective study. Int J Epidemiol 38, 848-54. [Medline] [CrossRef]

13) Esquirol Y, Bongard V, Mabile L, Jonnier B, Soulat JM, Perret B (2009) Shift work and metabolic syndrome: respective impacts of job strain, physical activity, and dietary rhythms. Chronobiol Int 26, 544-59. [Medline] [CrossRef]

14) Sookoian S, Gemma C, Fernández Gianotti T, Burgueño A, Alvarez A, González CD, Pirola CJ (2007) Effects of rotating shift work on biomarkers of metabolic syndrome and inflammation. J Intern Med 261, 285-92. [Medline] [CrossRef]

15) Violanti JM, Burchfiel CM, Hartley TA, Mnatsakanova A, Fekedulegn D, Andrew ME, Charles LE, Vila BJ (2009) Atypical work hours and metabolic syndrome among police officers. Arch Environ Occup Health 64, 194-201. [Medline] [CrossRef]

16) Chen JD, Lin YC, Hsiao ST (2010) Obesity and high blood pressure of 12-hour night shift female clean-room workers. Chronobiol Int 27, 334-44. [Medline] [CrossRef]

17) The Occupational and Safety and Health Act. The Ministry of Employment and Labor of Korea; 2015.

18) Moy FM, Bulgiba A (2010) The modified NCEP ATP III criteria maybe better than the IDF criteria in diagnosing Metabolic Syndrome among Malays in Kuala Lumpur. BMC Public Health 10, 678. [Medline] [CrossRef]

19) The Korean version of the international physical activity questionnaire (IPAQ), short form. The Korean National Health Insurance Service; 2015.

20) Guidelines for data processing and analysis of the International Physical Activity Questionnaire (IPAQ). The IPAQ group; 2005.

21) Bastien $\mathrm{CH}$, Vallières A, Morin CM (2001) Validation of the Insomnia Severity Index as an outcome measure for insomnia research. Sleep Med 2, 297-307. [Medline] [CrossRef]

22) Cho YW, Song ML, Morin CM (2014) Validation of a Korean version of the insomnia severity index. J Clin Neurol 10, 210-5. [Medline] [CrossRef]

23) Boivin DB, Boudreau P (2014) Impacts of shift work on sleep and circadian rhythms. Pathol Biol (Paris) 62, 292 301. [Medline] [CrossRef]

24) Kim TW, Jeong JH, Hong SC (2015) The impact of sleep and circadian disturbance on hormones and metabolism. Int J Endocrinol 2015, 591729. [Medline] [CrossRef]

25) Morris CJ, Purvis TE, Hu K, Scheer FAJL (2016) Circadian misalignment increases cardiovascular disease risk factors in humans. Proc Natl Acad Sci USA 113, E1402-11. [Medline] [CrossRef]

26) Scheer FAJL, Hilton MF, Mantzoros CS, Shea SA (2009) Adverse metabolic and cardiovascular consequences of circadian misalignment. Proc Natl Acad Sci USA 106, $4453-$ 8. [Medline] [CrossRef]

27) Eastman CI (2016) How to reduce circadian misalignment 
in rotating shift workers. ChronoPhysiol Ther 6, 41-6. [CrossRef]

28) Chang JH, Huang PT, Lin YK, Lin CE, Lin CM, Shieh YH, Lin YC (2015) Association between sleep duration and sleep quality, and metabolic syndrome in Taiwanese police officers. Int J Occup Med Environ Health 28, 1011-23. [Medline] [CrossRef]

29) Wolk R, Somers VK (2007) Sleep and the metabolic syndrome. Exp Physiol 92, 67-78. [Medline] [CrossRef]

30) Jennings JR, Muldoon MF, Hall M, Buysse DJ, Manuck SB (2007) Self-reported sleep quality is associated with the metabolic syndrome. Sleep 30, 219-23. [Medline] [CrossRef]

31) Gagnon C, Bélanger L, Ivers H, Morin CM (2013) Validation of the Insomnia Severity Index in primary care. J Am Board Fam Med 26, 701-10. [Medline] [CrossRef]

32) Bushnell PT, Colombi A, Caruso CC, Tak S (2010) Work schedules and health behavior outcomes at a large manufacturer. Ind Health 48, 395-405. [Medline] [CrossRef]

33) Morikawa Y, Nakamura K, Sakurai M, Nagasawa SY, Ishizaki M, Nakashima M, Kido T, Naruse Y, Nakagawa H (2014) The effect of age on the relationships between workrelated factors and heavy drinking. J Occup Health 56, 141-9. [Medline] [CrossRef]

34) Nea FM, Kearney J, Livingstone MB, Pourshahidi LK, Corish CA (2015) Dietary and lifestyle habits and the associated health risks in shift workers. Nutr Res Rev 28, 143 66. [Medline] [CrossRef]

35) Bae MJ, Song YM, Shin JY, Choi BY, Keum JH, Lee EA (2017) The association between shift work and health behavior: findings from the Korean national health and nutrition examination survey. Korean J Fam Med 38, 86-92. [Medline] [CrossRef]

36) Ramin C, Devore EE, Wang W, Pierre-Paul J, Wegrzyn LR, Schernhammer ES (2015) Night shift work at specific age ranges and chronic disease risk factors. Occup Environ Med 72, 100-7. [Medline] [CrossRef]

37) Hulsegge G, Gupta N, Holtermann A, Jørgensen MB, Proper KI, van der Beek AJ (2017) Shift workers have similar leisure-time physical activity levels as day workers but are more sedentary at work. Scand J Work Environ Health 43, 127-35. [Medline] [CrossRef]

38) The 2015 survey report on labor conditions by employment type. The Korean Ministry of Employment and Labor; 2016.

39) Kawada $T$, Otsuka $T$, Inagaki $H$, Wakayama $Y$, Katsumata M, Li Q, Li YJ (2010) A cross-sectional study on the shift work and metabolic syndrome in Japanese male workers. Aging Male 13, 174-8. [Medline] [CrossRef]

40) Lin YC, Hsiao TJ, Chen PC (2009) Persistent rotating shiftwork exposure accelerates development of metabolic syndrome among middle-aged female employees: a five-year follow-up. Chronobiol Int 26, 740-55. [Medline] [CrossRef]

41) Puttonen S, Viitasalo K, Härmä M (2012) The relationship between current and former shift work and the metabolic syndrome. Scand J Work Environ Health 38, 343-8. [Medline] [CrossRef]

42) Lennernäs M, Hambraeus L, Akerstedt T (1995) Shift related dietary intake in day and shift workers. Appetite 25, 253-65. [Medline] [CrossRef]

43) Morikawa Y, Miura K, Sasaki S, Yoshita K, Yoneyama S, Sakurai M, Ishizaki M, Kido T, Naruse Y, Suwazono Y, Higashiyama M, Nakagawa H (2008) Evaluation of the effects of shift work on nutrient intake: a cross-sectional study. J Occup Health 50, 270-8. [Medline] [CrossRef]

44) Waterhouse J, Buckley P, Edwards B, Reilly T (2003) Measurement of, and some reasons for, differences in eating habits between night and day workers. Chronobiol Int 20, 1075-92. [Medline] [CrossRef] 